Research Article

\title{
Dynamic Analysis of Metro Train-Monolithic Bed Track System under Tunnel Differential Settlement
}

\author{
Jiqing Jiang $\mathbb{D}^{1},{ }^{1}$ Beibei Dong $\mathbb{D}^{2},{ }^{2}$ Zhi Ding, ${ }^{1}$ Gang Wei $\mathbb{D}^{1},{ }^{1}$ He Zhang $\mathbb{D}^{2},{ }^{2}$ and Juan Liao ${ }^{1}$ \\ ${ }^{1}$ Department of Civil Engineering, Zhejiang University City College, Hangzhou 310015, China \\ ${ }^{2}$ College of Civil Engineering and Architecture, Zhejiang University, Hangzhou 310058, China
}

Correspondence should be addressed to Gang Wei; weig@zucc.edu.cn and He Zhang; zjuzhanghe@zju.edu.cn

Received 9 November 2019; Revised 23 April 2020; Accepted 6 May 2020; Published 4 June 2020

Academic Editor: Lutz Auersch

Copyright $\odot 2020$ Jiqing Jiang et al. This is an open access article distributed under the Creative Commons Attribution License, which permits unrestricted use, distribution, and reproduction in any medium, provided the original work is properly cited.

\begin{abstract}
The metro tunnel lines built in a soft soil area may suffer from tunnel differential settlement due to the high compressibility of soft soil, the engineering constructions nearby tunnel lines, and the cyclic load of metro trains. In this paper, a dynamic coupling model for a metro train-monolithic bed track system under tunnel differential settlement is established. A cosine function is introduced to simulate a real settlement curve measured from a metro tunnel in southern China, and the vibration performance of the train-track system under tunnel settlements is investigated in both the time domain and frequency domain. Based on the standards for the train safety and passengers' comfort, the speed limit for the metro train traveling on a monolithic bed track with different settlement distributions are concluded. The present research could be useful for the operation and maintenance of metro tunnels in soft soil areas.
\end{abstract}

\section{Introduction}

In recent years, the urban rail transit systems have been developed rapidly, especially in cities with high population density. The metro tunnels are important parts of the urban rail transit system, which can greatly alleviate urban traffic pressure and promote public transportation [1]. However, it also brings new challenges to urban residents, such as environmental vibration or noise problems [2, 3]. In addition, for the metro tunnels constructed in thick soft deposit areas (such as the cities in southern China) [4-6], it may suffer from tunnel differential settlement due to the high compressibility of soft soils, the differences in soil properties, engineering constructions near the tunnels [7, 8], and the cyclic load of metro trains [9]. The differential settlement of tunnels may lead to the deformation of the metro track, which can aggravate the train-track vibration and cause the damage of tunnel structures.

The problems related to differential settlement of the railway system have attracted wide attention of researchers. Frohling et al. [10] provided a simulation procedure for the dynamic analysis of the train-track system, which can predict the current and future performance of the vehicle/track system, including the track settlement. Based on the model test, finite element method, and principal stress axis rotation test, Momoya et al. [11] studied the settlement development mechanism of subgrade under train load. Abadi et al. [12] introduced several empirical ballast settlement models of ballasted tracks and evaluated the models with the laboratory test data.

The aforementioned researches are mainly focused on the ground railway system. For the differential settlement of metro tunnels, Huang et al. [13] investigated the train-induced vibration and the long-term settlement of a metro tunnel in saturated soft clay by using the finite element method. The differences between the $2 \mathrm{D}$ and $3 \mathrm{D}$ soil-water coupling analyses were studied, and the tunnel settlement was predicted by the 2D model. Jiang et al. [14] established a theoretical model for the metro train-track system, in which a quarter of a train vehicle was modelled as a rigid massspring-damping system and the rail-track system was simulated as two Euler beams supported by distributed spring-dashpot elements. The tunnel differential settlement was simulated by a cosine function, and the reaction forces of fasteners and the vertical displacement of the soil were calculated under different cases. 
In this paper, a dynamic coupling model is established for a metro train-monolithic bed track system. A differential settlement curve measured from a metro tunnel in southern China is considered, and the effect of tunnel differential settlement on the dynamic performance of train-monolithic bed track system is studied. According to the standards of the train safety and passengers' comfort, the speed limits for a metro train traveling on monolithic bed track under tunnel differential settlement are also suggested.

\section{Metro Train-Track Model and Solution}

2.1. Theoretical Model. Consider a metro train-monolithic bed track system, as shown in Figure 1. The train is composed of several cars, each of which consists of one carriage, two bogies, and four wheelsets. The carriage, bogies, and wheelsets are connected with each other by primary suspensions $k_{1}$ and $c_{1}$ and secondary suspensions $k_{2}$ and $c_{2}$, respectively. A total of 2 degrees of freedom are assigned to the carriage and also to each bogie to consider the vertical motion $v$ and the rotational motion $\psi$. For each wheelset, we consider only the vertical motion $v_{w}$. In this way, each train car is simulated by a rigid mass-spring-damping system with a total of 10 degrees of freedom [15-17].

Based on the Euler-Bernoulli beam theory, the rail is simplified as a simply supported beam with finite length $l_{r}$, bending stiffness $E_{r} I_{r}$, and linear mass density $\rho_{r} A_{r}$. The fasteners are simulated as discrete spring-dashpots with distance $l_{r s}$, stiffness $k_{r s}$, and damping coefficient $c_{r s}$. Since the monolithic track bed is integrated with the shield tunnel, a simply supported Timoshenko beam is used to model the monolithic bed (together with the tunnel lining), with bending stiffness $E_{h} I_{h}$, shear stiffness $\kappa A_{h} G_{h}$, and linear mass density $\rho_{h} A_{h}$. The soil surrounding the metro tunnel is modelled as uniform distributed spring-dashpots with the stiffness coefficient $k_{g}$ and damping coefficient $c_{g}$.

\subsection{Governing Equations and Solutions}

2.2.1. Equations for Metro Train and Rail. Based on the D'Alembert's principle, the dynamic equilibrium equation of the metro train is established as follows:

$$
\mathbf{M} \ddot{\mathbf{v}}+\mathbf{C} \dot{\mathbf{v}}+\mathbf{K v}=\mathbf{F},
$$

where $\mathbf{M}, \mathbf{C}$, and $\mathbf{K}$ are the mass matrix, damping matrix, and stiffness matrix of the train, respectively; $\mathbf{v}, \dot{\mathbf{v}}$, and $\ddot{\mathbf{v}}$ are the displacement vector, velocity vector, and acceleration vector of the train, respectively; and $\mathbf{F}$ is the external force vector of the train.

The equation of the rail can be written as follows:

$$
\begin{gathered}
E_{r} I_{r} \frac{\partial^{4} v_{r}(x, t)}{\partial x^{4}}+\rho_{r} A_{r} \frac{\partial^{2} v_{r}(x, t)}{\partial t^{2}}=F_{r}(x, t) \\
F_{r}(x, t)=\sum_{a=1}^{n_{c}} \sum_{i=1}^{4} P_{a, i}\left(x_{w, i}(t)\right) \delta\left(x-x_{w, i}\right)-\sum_{j=1}^{n_{r s}} P_{r s, j}(t) \delta\left(x-x_{r s, j}\right),
\end{gathered}
$$

where $E_{r} I_{r}$ is the bending stiffness of the rail; $\rho_{r} A_{r}$ is the linear mass density of the rail; $v_{r}$ is the vertical displacement of the rail; $F_{r}(x, t)$ is the external force applied on the rail; $x_{w, i}(t)$ is the position of the $i^{\text {th }}$ wheelset at time $t$, and $P_{a, i}\left(x_{w, i}(t)\right)$ is the wheel-rail contact force for the $i^{\text {th }}$ wheelset of the $a^{\text {th }}$ car; $x_{r s, j}$ is the position of the $j^{\text {th }}$ fastener, and $P_{r s, j}(t)$ is the corresponding fastener force of the $j^{\text {th }}$ fastener; and $n_{c}$ and $n_{r s}$ are the numbers of cars and fasteners, respectively. The expressions for the wheel-rail contact force $P_{a, i}\left(x_{w, i}(t)\right)$ and the fastener reaction force $P_{r s, j}(t)$ are respectively given by

$$
\begin{gathered}
P_{a, i}\left(x_{w, i}(t)\right)=k_{w r}\left(v_{w, a, i}(t)-\varepsilon\left(x_{w, a, i}\right) v_{r}\left(x_{w, a, i}, t\right)\right), \\
\varepsilon(x)= \begin{cases}1, & 0<x<l_{r}, \\
0, & x \leq 0 \text { and } x \geq l_{r},\end{cases} \\
P_{r s, j}(t)=k_{r s}\left[v_{r}\left(x_{r s, j}, t\right)-v_{h}\left(x_{r s, j}, t\right)\right]+c_{r s}\left[\dot{v}_{r}\left(x_{r s, j}, t\right)-\dot{v}_{h}\left(x_{r s, j}, t\right)\right],
\end{gathered}
$$

in which $k_{w r}$ is the wheel-rail contact stiffness; $x_{w, a, i}$ is the location of the $i^{\text {th }}$ wheelset of the $a^{\text {th }}$ car at arbitrary time $t$; $v_{w, a, i}(t)$ is the corresponding vertical displacement of the $i^{\text {th }}$ wheelset of the $a^{\text {th }}$ car; $v_{h}$ is the vertical displacement of the monolithic bed; $l_{r}$ is the length of the rail; and $k_{r s}$ and $c_{r s}$ are the stiffness coefficient and damping coefficient of rail fasteners, respectively.

\subsubsection{Equations for Monolithic Bed-Tunnel Lining System.} The metro monolithic bed is usually connected integrally with the tunnel lining. In this paper, we use a simply supported Timoshenko beam to model the monolithic bed and tunnel lining. The governing equation of the Timoshenko beam can be given by

$$
\left\{\begin{array}{l}
\kappa A_{h} G_{h}\left(\frac{\partial^{2} v_{h}(x, t)}{\partial x^{2}}-\frac{\partial \phi_{h}(x, t)}{\partial x}\right)=\rho_{h} A_{h} \frac{\partial^{2} v_{h}(x, t)}{\partial t^{2}}+F_{h}(x, t), \\
E_{h} I_{h} \frac{\partial^{2} \phi_{h}(x, t)}{\partial x^{2}}+\kappa A_{h} G_{h}\left(\frac{\partial v_{h}(x, t)}{\partial x}-\phi_{h}(x, t)\right)=\rho_{h} I_{h} \frac{\partial^{2} \phi_{h}(x, t)}{\partial t^{2}},
\end{array}\right.
$$

where $E_{h} I_{h}$ and $\kappa A_{h} G_{h}$ are the bending stiffness and shear stiffness of the monolithic track bed-tunnel lining system, respectively; $\rho_{h} A_{h}$ and $\rho_{h} I_{h}$ are the linear mass density and rotational inertia of the monolithic track bed-tunnel lining system, respectively; and $v_{h}$ and $\phi_{h}$ are the vertical displacement and rotational angle, respectively.

The external force $F_{h}(x, t)$ applied on the monolithic bed-tunnel lining system is written as follows:

$$
F_{h}(x, t)=\sum_{j=1}^{n_{r s}} P_{r s, j} \delta\left(x-x_{r s, j}\right)-k_{g} v_{h}(x, t)-c_{g} \dot{v}_{h}(x, t),
$$

where $k_{g}$ and $c_{g}$ are the stiffness coefficient and damping coefficient of the soil foundation, respectively, and $\dot{v}_{h}$ is the vertical velocity of the track bed-lining system. 


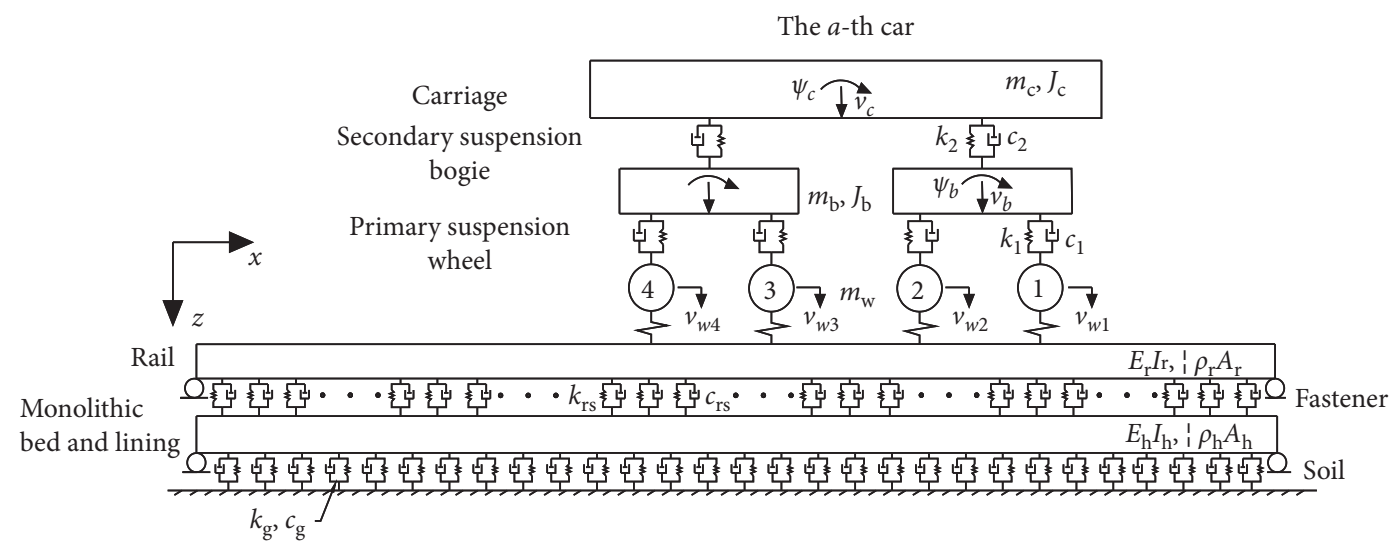

Figure 1: Model of a metro train-monolithic bed track system.

2.2.3. Solutions of Equations. As mentioned above, the rail is modelled as a simply supported Euler-Bernoulli beam. According to the modal superposition method, the vertical displacement of the rail can be assumed as

$$
v_{r}(x, t)=\sum_{u=1}^{m_{r}} V_{r, u}(x) q_{r, u}(t)
$$

in which $V_{r, u}(x)$ is the $u^{\text {th }}$ modal function of the rail displacement; $q_{r, u}(t)$ is the $u^{\text {th }}$ generalized function of the rail displacement; and $m_{r}$ is the mode number adopted in the calculation.

The vertical displacement of the monolithic track bedlining system can be similarly obtained by

$$
\left\{\begin{array}{l}
v_{h}(x, t)=\sum_{u=1}^{m_{t}} V_{h, u}(x) q_{h, u}(t), \\
\phi_{h}(x, t)=\sum_{u=1}^{m_{t}} \Phi_{h, u}(x) q_{h, u}(t),
\end{array}\right.
$$

where $V_{h, u}(x)$ and $\Phi_{h, u}$ are the $u^{\text {th }}$ modal functions of vertical displacement and rotational angle of the track bedlining system and $q_{h, u}(t)$ is the generalized function and $m_{t}$ is the total number of the mode functions of the track bedlining system.

By substituting equations (8) into (2), and then applying the orthogonality of the modal functions, we can obtain the ordinary differential equation of the rail as follows:

$$
\begin{aligned}
E_{r} I_{r}\left(\frac{k \pi}{l_{r}}\right)^{4} q_{r, k}(t)+\rho_{r} A_{r} \ddot{q}_{r, k}(t)= & \frac{2}{l_{r}} \sum_{a=1}^{n_{c}} \sum_{i=1}^{4} V_{r, k}\left(x_{w, a, i}\right) k_{w r}\left[v_{w, a, i}(t)-\sum_{u=1}^{m_{r}} V_{r, u}\left(x_{w, a, i}\right) q_{r, u}(t)\right] \\
& -\frac{2}{l_{r}} \sum_{j=1}^{n_{r s}} V_{r, k}\left(x_{r s, j}\right)\left\{\begin{array}{l}
k_{r s}\left[\sum_{u=1}^{m_{r}} V_{r, u}\left(x_{r s, j}\right) q_{r, u}(t)-\sum_{u=1}^{m_{t}} V_{h, u}\left(x_{r s, j}\right) q_{h, u}(t)\right] \\
+c_{r s}\left[\sum_{u=1}^{m_{r}} V_{r, u}\left(x_{r s, j}\right) \dot{q}_{r, u}(t)-\sum_{u=1}^{m_{t}} V_{h, u}\left(x_{r s, j}\right) \dot{q}_{h, u}(t)\right]
\end{array}\right\} .
\end{aligned}
$$

The ordinary equations for the monolithic track bedlining system can be similarly obtained by substituting equation (9) into equation (6).

$$
\begin{aligned}
& \int_{0}^{l_{r}}\left[\rho_{h} A_{h} V_{h, k}^{2}(x)+\rho_{h} I_{h} \Phi_{h, k}^{2}(x)\right] d x \cdot\left[\ddot{q}_{h, k}(t)+\omega_{h, k}^{2} q_{h, k}(t)\right]=-\frac{l_{r}}{2}\left[k_{g} q_{h, k}(t)+c_{g} \dot{q}_{h, k}(t)\right] \\
& \quad+\sum_{j=1}^{n_{r s}} V_{h, k}\left(x_{r s, j}\right)\left\{\begin{array}{l}
k_{r s}\left[\sum_{u=1}^{m_{r}} V_{r, u}\left(x_{r s, j}\right) q_{r, u}(t)-\sum_{u=1}^{m_{t}} V_{h, u}\left(x_{r s, j}\right) q_{h, u}(t)\right] \\
+c_{r s}\left[\sum_{u=1}^{m_{r}} V_{r, u}\left(x_{r s, j}\right) \dot{q}_{r, u}(t)-\sum_{u=1}^{m_{t}} V_{h, u}\left(x_{r s, j}\right) \dot{q}_{h, u}(t)\right]
\end{array}\right\} .
\end{aligned}
$$


Combining equations (10) and (11) with equation (1), the global governing equations for the metro train-monolithic bed track system can be derived. By virtue of the Newmark- $\beta$ method, the dynamic responses of the metro train and the monolithic bed track system can finally be calculated.

\section{Metro Train-Track System under Tunnel Differential Settlement}

The metro tunnels built in a soft clay area usually suffer from long-term settlement and deformation-related groundwater infiltration. Significant differential settlement of metro tunnels has been found in cities such as Shanghai and Nanjing in southeastern China $[13,14]$. The tunnel differential settlement can increase the vibration of the metro train-track system and damage the tunnel structures. In order to investigate the influence of tunnel differential settlement on the vibration performance of the metro train-monolithic bed track system, a theoretical model for tunnel differential settlement is introduced, as shown in Figure 2. The following assumptions are adopted for the tunnel differential settlement model [14]: (1) the deformation of the rail is consistent with the tunnel differential settlement; (2) all the supporting elements/layers (including fasteners and soil) remain in good contact with structures; (3) the rail deformation caused by the tunnel settlement is regarded as an initial deformation of the rail, which is similar to the track irregularity.

According to the assumptions described above, the initial track deformation considering both the tunnel differential settlement and random track irregularity is written as

$$
r(x)=r_{1}(x)+h(x)
$$

where $r_{1}(x)$ is the random track irregularity related to the track quality which is referenced from the US Class 6 railways [18] and $h(x)$ is the track deformation caused by the tunnel differential settlement.

\section{Numerical Results and Discussion}

First, a simple numerical example for a metro trainmonolithic bed track system without tunnel settlement is studied to validate the numerical methods proposed in this paper. The vibration responses of the metro train-track system are calculated and compared with those obtained by Wei et al. [19]. Here, a metro train grouped with two cars is considered, and the train speed is assumed to be $20 \mathrm{~m} / \mathrm{s}$. The random track irregularity of the US Class 5 railways is adopted, and the train-track parameters used for the numerical validation are the same as those in [19], as listed in Table 1 .

The rail acceleration and the wheel-rail contact force obtained by the present method are shown in Figure 3. It is concluded that the present results are generally consistent with those in [19], but there are still some numerical differences between them, as shown in Table 2. The main reason for the numerical differences is that some of the calculation parameters were not mentioned in [19], e.g., the bending stiffness and shear stiffness of the tunnel, the distance between fasteners, and the equivalent stiffness of the soil.
Therefore, numerical deviations may exist between these two results.

4.1. Parameters of Train-Track System with Tunnel Settlement. Figure 4(a) shows the measured differential settlement curve for a metro tunnel with monolithic bed track in southern China, and Figure 4(b) shows the fitting curve of that in Figure 4(a) which can be represented by a polynomial function. This metro tunnel is constructed by the shield method and is buried in soft deposit with high compressibility, low permeability, and low shear strength. The settlement of the tunnel was observed during the construction of the tunnel, and it became severe due to the cyclic dynamic loading of the metro train. So far, the maximum differential settlement of the tunnel has exceeded $100 \mathrm{~mm}$, and it is still developing according to the monitoring records.

The material and geometric parameters of the metro train-monolithic bed track system used in the numerical examples are mainly referenced from this real monolithic bed track tunnel in southern China, and the detail values are listed in Table 3. The cross-section of the metro tunnel is circular, with an outer diameter of $6.2 \mathrm{~m}$ and the thickness of $0.35 \mathrm{~m}$. The tunnel lining is precast with C50 concrete and its modulus of elasticity is taken as $34.4 \mathrm{GPa}$. The $B$-type metro train is grouped with two cars, and the train speed is assumed to be $72 \mathrm{~km} / \mathrm{h}$. The length of the rail is taken as $l_{r}=325 \mathrm{~m}$, which is the same as the length of the monolithic bed. The type of fasteners is DTVI2-1 with a spacing of $0.625 \mathrm{~m}$, i.e., the rail and monolithic track bed are connected to each other by 520 fasteners.

For the numerical analysis in this paper, the tunnel differential settlement from section $585.901 \mathrm{~m}$ to section $790.901 \mathrm{~m}$ in Figure $4(\mathrm{a})$ is considered and the corresponding fitting curve is shown in Figure 4(b). The initial time $t=0$ is taken as the moment when the first wheelset of the train arrives at the position $l_{r}=45 \mathrm{~m}$ to reduce the boundary influence on the calculation results.

4.2. Time-Domain Analysis. The vibration responses of the metro train-monolithic bed track system under tunnel differential settlement are calculated. Here, the random track irregularity is considered based on the power spectral density of the US Class 6 railways. As shown in Figure 5, the vertical acceleration of the first carriage increases obviously from $0.109 \mathrm{~m} / \mathrm{s}^{2}$ to $0.14 \mathrm{~m} / \mathrm{s}^{2}$ at $t=1.5 \mathrm{~s}$ (the moment when the first wheelset enters the differential settlement section). The largest change occurs around $t=2.5 \mathrm{~s}$ due to the complex effects combined with the differential settlement and random irregularity of the track. After the train leaves the settlement section at $t=13.4 \mathrm{~s}$, the effect of tunnel settlement on the carriage acceleration will gradually vanish, as shown in Figure 5.

It is also found that the carriage acceleration is sensitive to the local curvature of the tunnel settlement curve. The variation of the carriage acceleration is relatively small when the settlement curve changes smoothly. However, the carriage acceleration varies significantly even for a slight irregularity in the settlement curve, as shown in Figure 5, at 


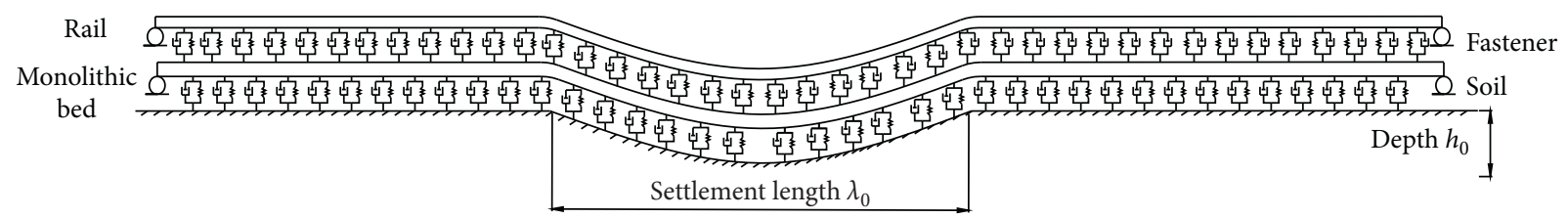

Figure 2: Model of the metro train-monolithic bed track system under tunnel differential settlement.

TABle 1: Parameters of the metro train-monolithic track system in [19].

\begin{tabular}{|c|c|c|c|}
\hline Parameter & Value & Parameter & Value \\
\hline Axle weight $(\mathrm{kN})$ & 132 & Length of train $(\mathrm{m})$ & 20 \\
\hline Distance between two bogies of a carriage (m) & 12.6 & Distance between two wheelsets of a bogie $(\mathrm{m})$ & 2.2 \\
\hline Stiffness of primary suspension $\left(\mathrm{kN} \cdot \mathrm{m}^{-1}\right)$ & 1500 & Damping of primary suspension $\left(\mathrm{kN} \cdot \mathrm{s} \cdot \mathrm{m}^{-1}\right)$ & 50 \\
\hline Stiffness of secondary suspension $\left(\mathrm{kN} \cdot \mathrm{m}^{-1}\right)$ & 250 & Damping of secondary suspension $\left(\mathrm{kN} \cdot \mathrm{s} \cdot \mathrm{m}^{-1}\right)$ & 30 \\
\hline Linear mass density of rail $\left(\mathrm{kg} \cdot \mathrm{m}^{-1}\right)$ & 60 & Elastic modulus of rail $(\mathrm{GPa})$ & 210 \\
\hline Moment of inertia of rail $\left(\mathrm{m}^{4}\right)$ & $3.217 \times 10^{-5}$ & Radius of train wheel (m) & 0.42 \\
\hline Stiffness of fastener $\left(\mathrm{MN} \cdot \mathrm{m}^{-1}\right)$ & 52.5 & Damping of fastener $\left(\mathrm{kN} \cdot \mathrm{s} \cdot \mathrm{m}^{-1}\right)$ & 75 \\
\hline Mass density of tunnel lining $\left(\mathrm{kg} \cdot \mathrm{m}^{-3}\right)$ & 2500 & Elastic modulus of tunnel lining (GPa) & 30 \\
\hline
\end{tabular}

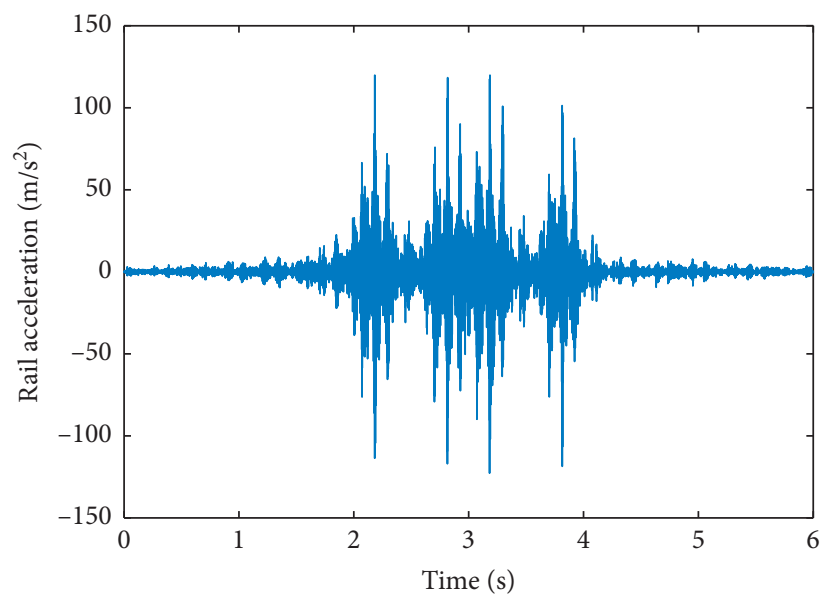

(a)

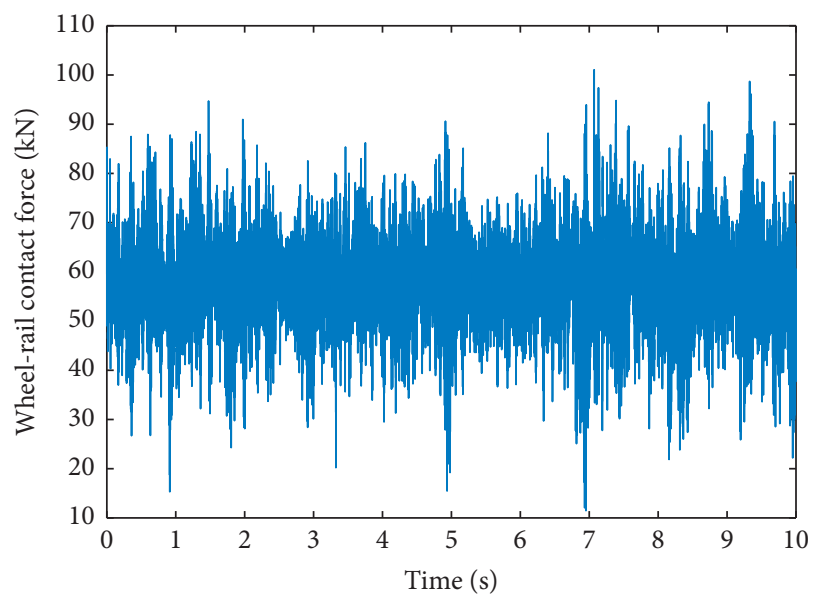

(b)

FIGURE 3: Vibration responses of the metro train-monolithic bed track system. (a) Vertical acceleration at the midpoint of the rail. (b) Wheel-rail contact force.

TABle 2: Comparison of vibration responses of the metro train-monolithic bed track system.

\begin{tabular}{lcc}
\hline & Wei et al. [19] & Present \\
\hline Acceleration at the midpoint of the rail & $-181 \mathrm{~m} / \mathrm{s}^{2} \sim 155 \mathrm{~m} / \mathrm{s}^{2}$ & $-124 \mathrm{~m} / \mathrm{s}^{2} \sim 122 \mathrm{~m} / \mathrm{s}^{2}$ \\
Wheel-rail contact force & $11 \mathrm{kN} \sim 134 \mathrm{kN}$ & $12 \mathrm{kN} \sim 103 \mathrm{kN}$ \\
\hline
\end{tabular}

$t=10.2 \mathrm{~s}$ (corresponding to the position of $l_{r}=249 \mathrm{~m}$ in Figure 4(b)). In this case, the passengers' comfort will be adversely affected.

Figure 6 shows the wheel-rail contact force of the first wheelset. Similar to the carriage acceleration, the tunnel settlement mainly affects the wheel-rail contact force during the period from $1.5 \mathrm{~s}$ to $13.4 \mathrm{~s}$. When the first wheelset of the train enters the settlement section at $t=1.5 \mathrm{~s}$, the contact force decreases significantly from $77 \mathrm{kN}$ to $49 \mathrm{kN}$. The minimum wheel-track contact force is $41.94 \mathrm{kN}$ at $t=2.5 \mathrm{~s}$, which may lead to derailment and is dangerous for subway operation.

The vertical displacement and acceleration at the midpoint of the rail are also calculated. As shown in Figures 7 and 8, the tunnel differential settlement has little effect on the vertical displacement of the rail but has significant influence on the rail acceleration. For three specific moments in Figure 8, i.e., point A (the moment when the first wheelset arrives at the midpoint of the rail), point $B$ (the moment when the midpoint of the train arrives at the 


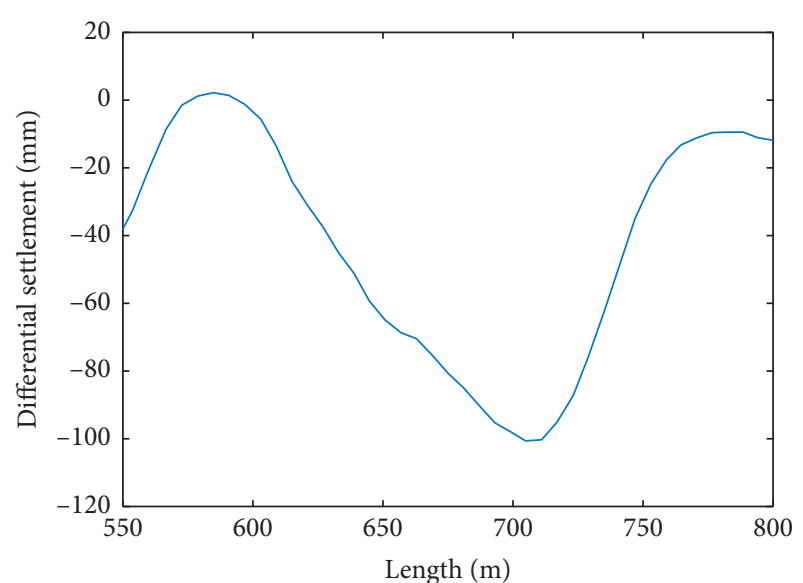

(a)

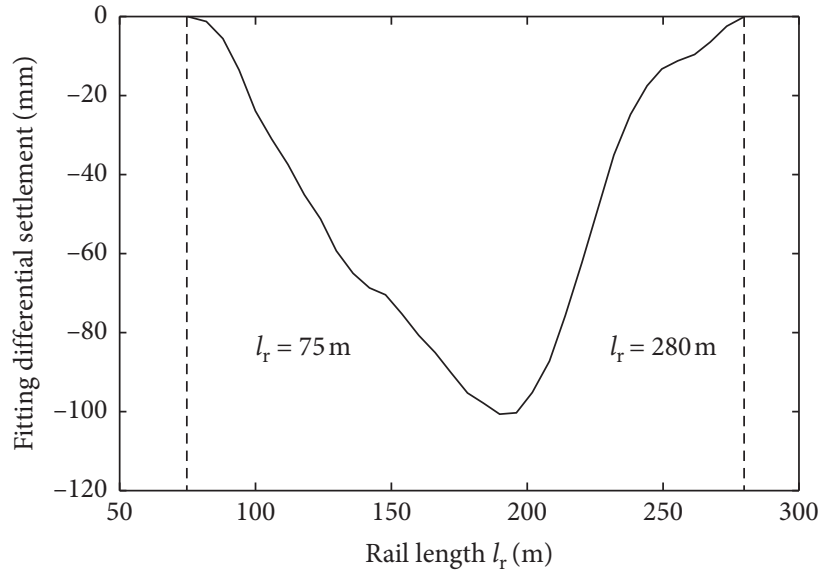

(b)

Figure 4: Differential settlement curves for a metro tunnel in southern China. (a) Measured curve of tunnel differential settlement. (b) Fitting differential settlement.

TABLE 3: Material and geometric parameters of the metro train-monolithic track system.

\begin{tabular}{|c|c|c|c|}
\hline Parameter & Value & Parameter & Value \\
\hline Mass of carriage $(\mathrm{t})$ & 39.54 & Mass of bogie $(\mathrm{t})$ & 3.52 \\
\hline Moment of inertia of carriage $\left(t \cdot \mathrm{m}^{2}\right)$ & 1328 & Moment of inertia of bogie $\left(t \cdot \mathrm{m}^{2}\right)$ & 1.76 \\
\hline Length of carriage $(\mathrm{m})$ & 19 & Mass of a wheel axle (t) & 1.539 \\
\hline Distance between two bogies of a carriage (m) & 12.6 & Distance between two wheelsets of a bogie (m) & 2.3 \\
\hline Stiffness of primary suspension $\left(\mathrm{kN} \cdot \mathrm{m}^{-1}\right)$ & 1700 & Damping of primary suspension $\left(\mathrm{kN} \cdot \mathrm{s} \cdot \mathrm{m}^{-1}\right)$ & 60 \\
\hline Stiffness of secondary suspension $\left(\mathrm{kN} \cdot \mathrm{m}^{-1}\right)$ & 450 & Damping of secondary suspension $\left(\mathrm{kN} \cdot \mathrm{s} \cdot \mathrm{m}^{-1}\right)$ & 60 \\
\hline Linear mass density of rail $\left(\mathrm{kN} \cdot \mathrm{m}^{-1}\right)$ & 121.28 & Bending stiffness of rail $\left(\mathrm{kN} \cdot \mathrm{m}^{2}\right)$ & 12400 \\
\hline Stiffness of rail pad $\left(\mathrm{kN} \cdot \mathrm{m}^{-1}\right)$ & 100000 & Damping of rail pad $\left(\mathrm{kN} \cdot \mathrm{s} \cdot \mathrm{m}^{-1}\right)$ & 50 \\
\hline Stiffness of wheel/rail interaction $\left(\mathrm{kN} \cdot \mathrm{m}^{-1}\right)$ & $1.2 \times 10^{6}$ & $\begin{array}{l}\text { Linear mass density of monolithic track bed-tunnel lining } \\
\text { system }\left(\mathrm{t} \cdot \mathrm{m}^{-1}\right)\end{array}$ & 18.6 \\
\hline $\begin{array}{l}\text { Bending stiffness of monolithic track bed-tunnel lining } \\
\text { system }\left(\mathrm{kN} \cdot \mathrm{m}^{2}\right)\end{array}$ & $2.23 \times 10^{8}$ & $\begin{array}{l}\text { Shear stiffness of monolithic track bed-tunnel lining } \\
\text { system }\left(\mathrm{kN} \cdot \mathrm{m}^{2}\right)\end{array}$ & $1.74 \times 10^{7}$ \\
\hline Stiffness of soil foundation $\left(\mathrm{MN} \cdot \mathrm{m}^{-1}\right)$ & 100 & Damping of soil foundation $\left(\mathrm{kN} \cdot \mathrm{s} \cdot \mathrm{m}^{-1}\right)$ & 3750 \\
\hline
\end{tabular}

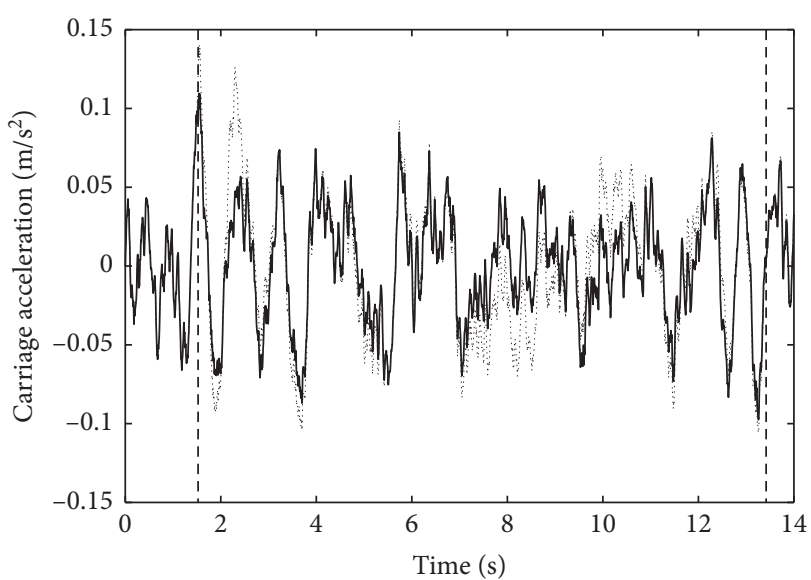

FIGURE 5: Effects of tunnel differential settlement on vertical acceleration of the first carriage (— without differential settlement; ...... with differential settlement; --- the moment when the train enters or leaves the settlement zone).

midpoint of the rail), and point $C$ (the moment when the last wheelset arrives at the midpoint of the rail), the corresponding accelerations increase from $252 \mathrm{~m} / \mathrm{s}^{2}, 299 \mathrm{~m} / \mathrm{s}^{2}$, and $357 \mathrm{~m} / \mathrm{s}^{2}$ to $388 \mathrm{~m} / \mathrm{s}^{2}, 349 \mathrm{~m} / \mathrm{s}^{2}$, and $456 \mathrm{~m} / \mathrm{s}^{2}$, respectively. Among them, the maximum increase rate of the rail acceleration is $54 \%$.

4.3. Frequency-Domain Analysis. In order to further study the dynamic characteristics of the train-monolithic bed track system under tunnel differential settlement, the vibration of the train-track system in the frequency domain is also analyzed [20,21]. Figure 9 shows the frequency spectrum of the wheel-rail contact force. It is found that the tunnel differential settlement has obvious effect on the high-frequency part of the wheel-rail contact force. In detail, the frequency amplitude between $300 \mathrm{~Hz}$ and $400 \mathrm{~Hz}$ increases from $210 \mathrm{~N}$ to $450 \mathrm{~N}$, while the frequency amplitude between $600 \mathrm{~Hz}$ and $700 \mathrm{~Hz}$ increases from $405 \mathrm{~N}$ to $1180 \mathrm{~N}$, with a maximum increase rate of $191 \%$.

A similar phenomenon can be observed in the $1 / 3$ octave band of the wheel-rail contact force, as shown in Figure 10. It can be found that the amplitude increases by $38.8 \%$ between $250 \mathrm{~Hz}$ and $800 \mathrm{~Hz}$. It is concluded that the tunnel differential settlement can amplify the dynamic reaction between the train wheel and the rail, thereby increasing the damage/ 


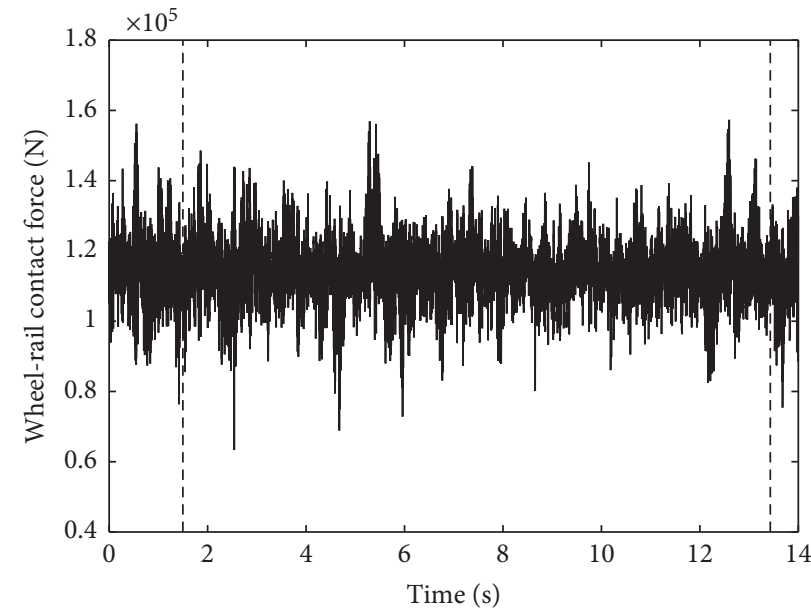

(a)

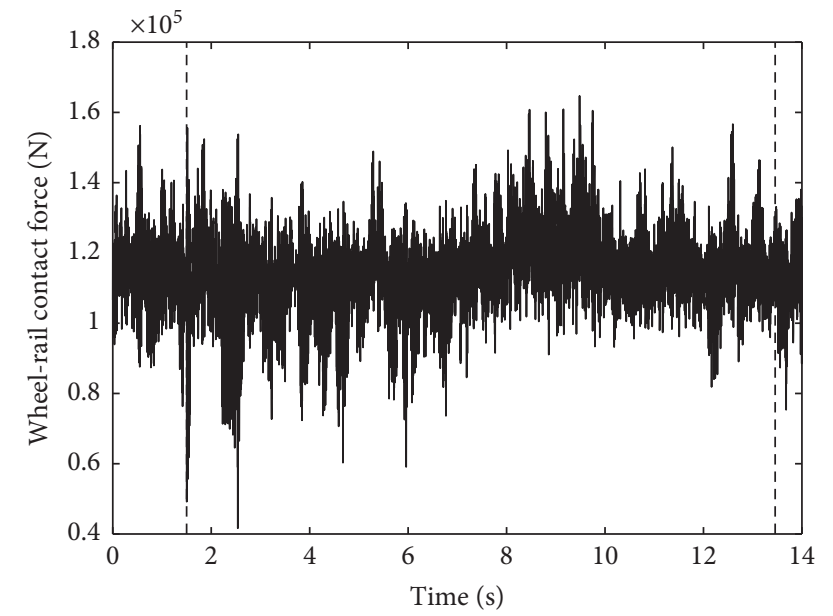

(b)

Figure 6: Effects of tunnel differential settlement on the wheel-rail contact force (--- the moment when the train enters or leaves the settlement zone). (a) Without differential settlement. (b) With differential settlement.

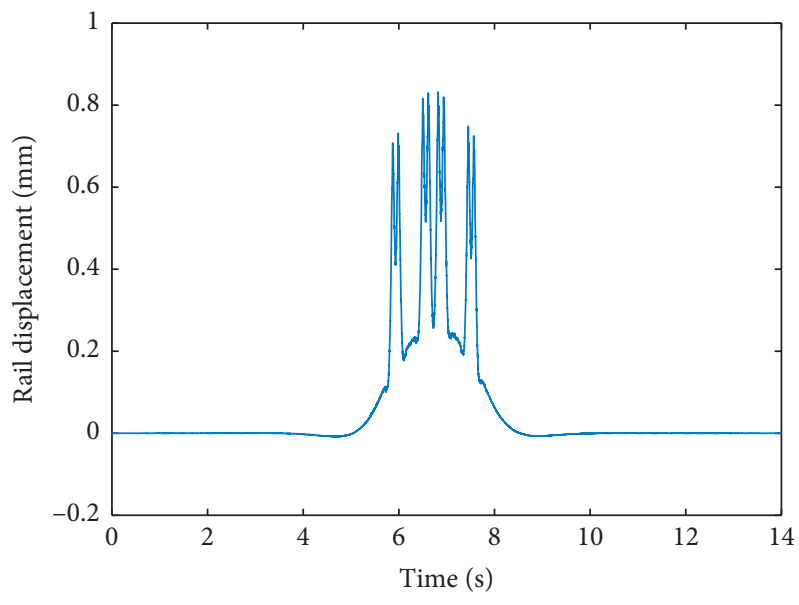

(a)

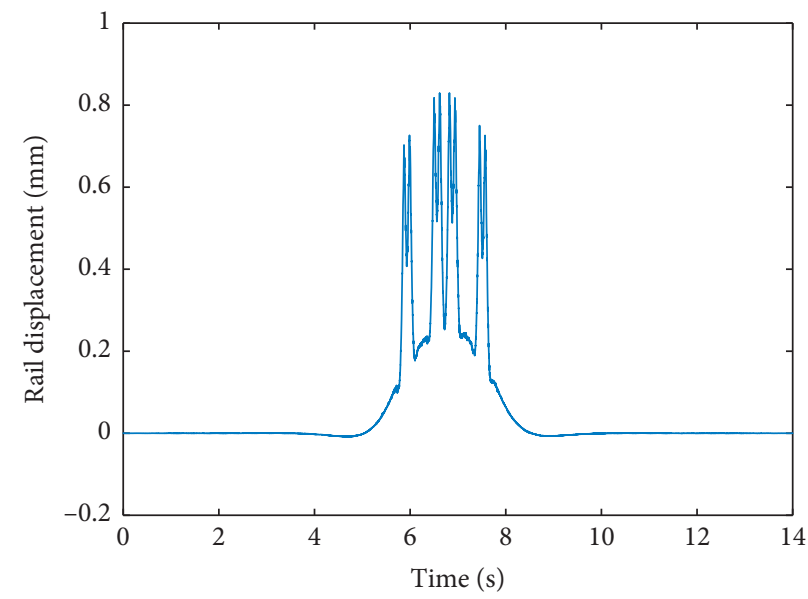

(b)

FIGURE 7: Effect of tunnel differential settlement on the vertical displacement at the midpoint of the rail. (a) Without differential settlement. (b) With differential settlement.

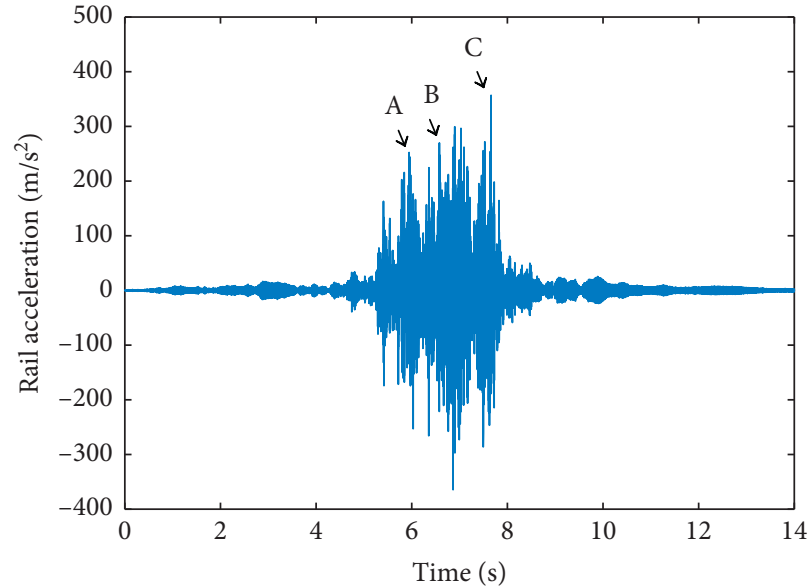

(a)

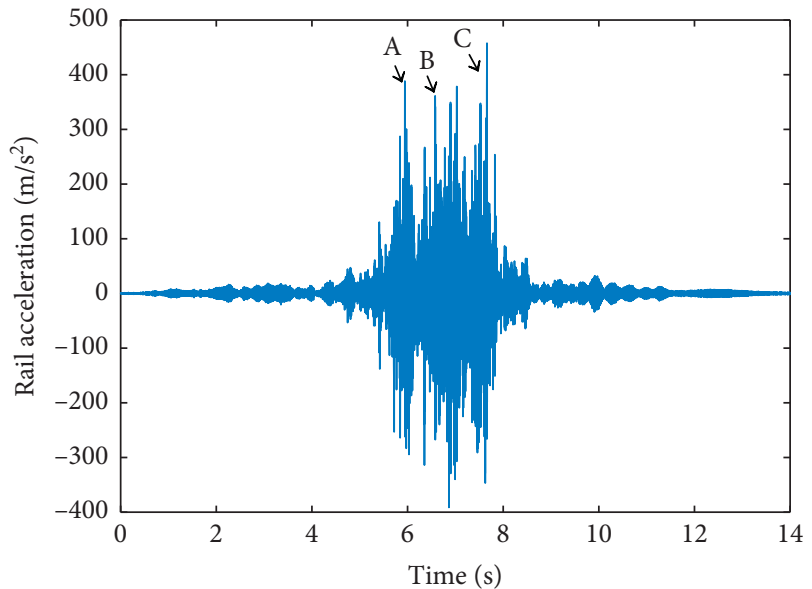

(b)

FIGURE 8: Effect of tunnel differential settlement on the vertical acceleration at the midpoint of the rail. (a) Without differential settlement. (b) With differential settlement. 


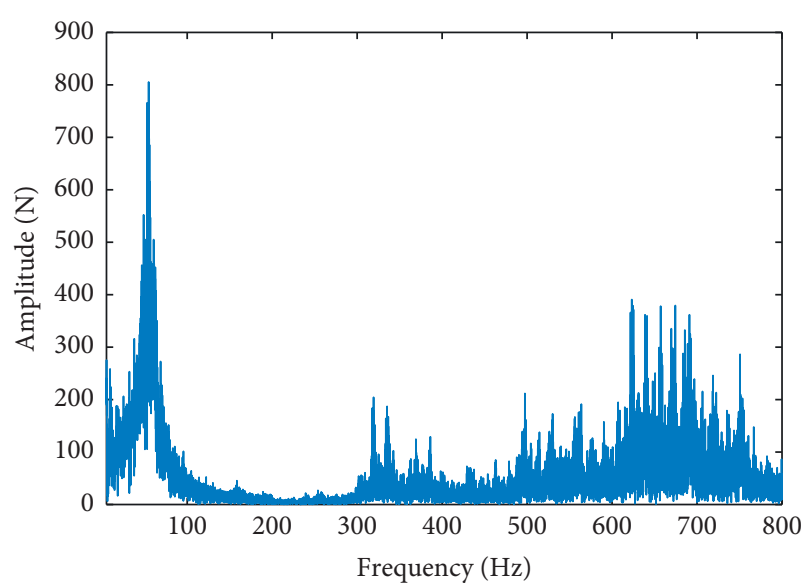

(a)

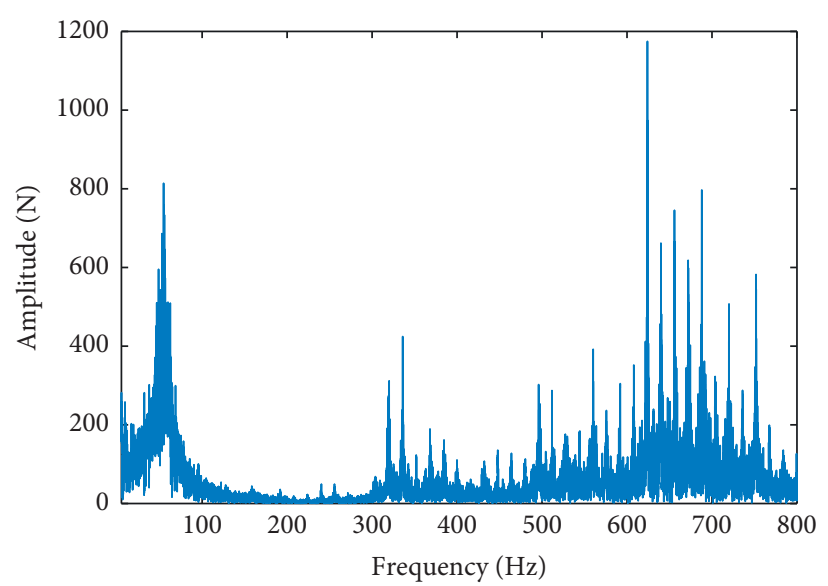

(b)

Figure 9: Effect of tunnel differential settlement on the frequency spectrum of the wheel-rail contact force. (a) Without differential settlement. (b) With differential settlement.

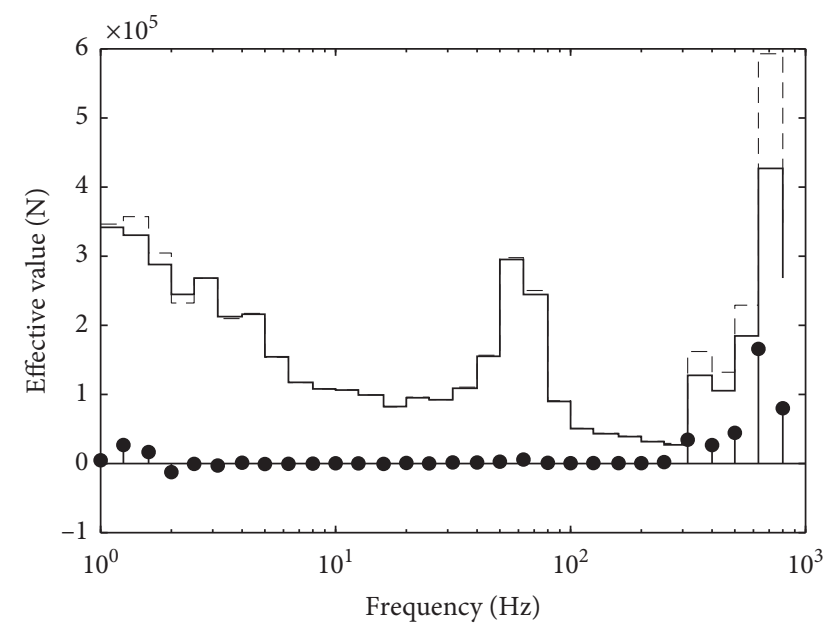

Figure 10: 1/3 Octave band of the wheel-rail contact force (without settlement; - - - with differential settlement; $\bullet$ - differences between two cases).

loss of the wheel and the rail track and reducing their service life.

Figure 11 shows the $1 / 3$ octave bands of the rail acceleration and lining acceleration under different conditions. It can be seen from Figure 11 that the tunnel differential settlement can also increase vibration levels of the rail acceleration and lining acceleration in the high-frequency region but has little effect on the low-frequency region. As shown in Figures 11(a) and 11(b), the rail acceleration increases by $2.569 \mathrm{~dB}$ at $500 \mathrm{~Hz}$, and the vibration level of the lining acceleration increases by $10.6 \%$ at $630 \mathrm{~Hz}$. It is noted that the increase of vibration level in the high-frequency band can intensify environmental noises and may have adverse effect on the lives of residents near the metro lines.

For the dynamic analysis of the train-track system under different settlement conditions, a trigonometric function is usually adopted for the theoretical modelling of the tunnel settlement [12]. In order to verify the trigonometric model and extend the present research, this paper compares the numerical results obtained by the trigonometric model with those obtained by the real tunnel settlement curve. Here, we assume a cosine function $h(x)$ expressed as follows:

$$
h(x)= \begin{cases}0, & \text { if } x<x_{0}, x>x_{0}+\lambda_{0}, \\ \frac{h_{0}}{2}\left(1-\cos \left(\frac{2 \pi\left(x-x_{0}\right)}{\lambda_{0}}\right)\right), & \text { if } x_{0} \leq x \leq x_{0}+\lambda_{0},\end{cases}
$$

where $h_{0}=100 \mathrm{~mm}$ is the depth of the tunnel settlement and $\lambda_{0}=200 \mathrm{~m}$ is the distribution length of the settlement, as shown in Figure 2 and $x_{0}=75 \mathrm{~m}$ is the position where the tunnel settlement starts.

Figure 12 shows the comparison of the theoretical and practical tunnel settlement curves. The dynamic responses of the metro train-track system due to the theoretical and real tunnel settlement curves are studied both in the time and frequency domains. It is found that the vibration difference due to the two settlement curves is small. Figure 13 shows the $1 / 3$ octave bands of wheel-rail contact force under the theoretical and practical tunnel settlement curves. It is found that the difference in the frequency bands of wheel-rail contact force is less than $5 \%$. Therefore, it is confirmed that the cosine function can be used as an approximation of the practical tunnel settlement curve. This allows for further theoretical analysis to investigate the influence of different tunnel settlements on the dynamic characteristics of the train-track system.

\subsection{Effects of Tunnel Settlement Waveform on Train-Track} System. As mentioned in the previous section, the practical tunnel settlement curve used in this paper can be approximated by a cosine function. Therefore, we can use the cosine model to theoretically study the dynamic responses of the metro train-track system due to various tunnel differential settlements. In this section, five different cases are discussed 


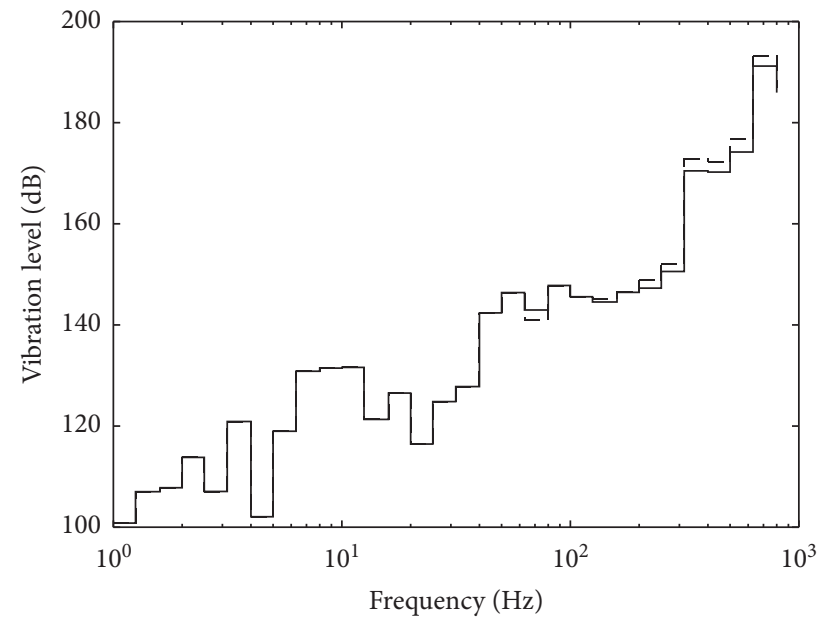

(a)

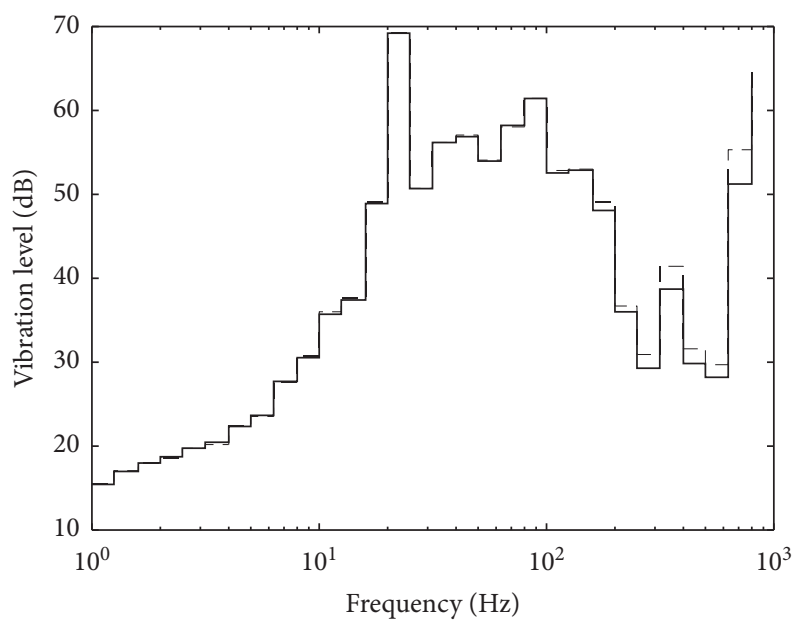

(b)

Figure 11: 1/3 Octave band acceleration of the metro track system (— without differential settlement; - - - with differential settlement). (a) Rail acceleration at the midpoint. (b) Tunnel lining acceleration at the midpoint.

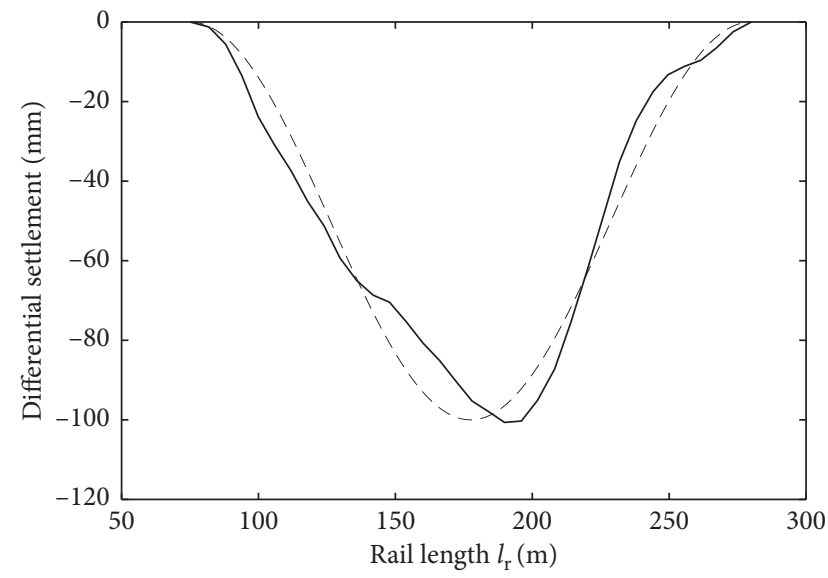

FIGURE 12: Comparison of theoretical tunnel settlement (-- $)$ and practical tunnel settlement (-).

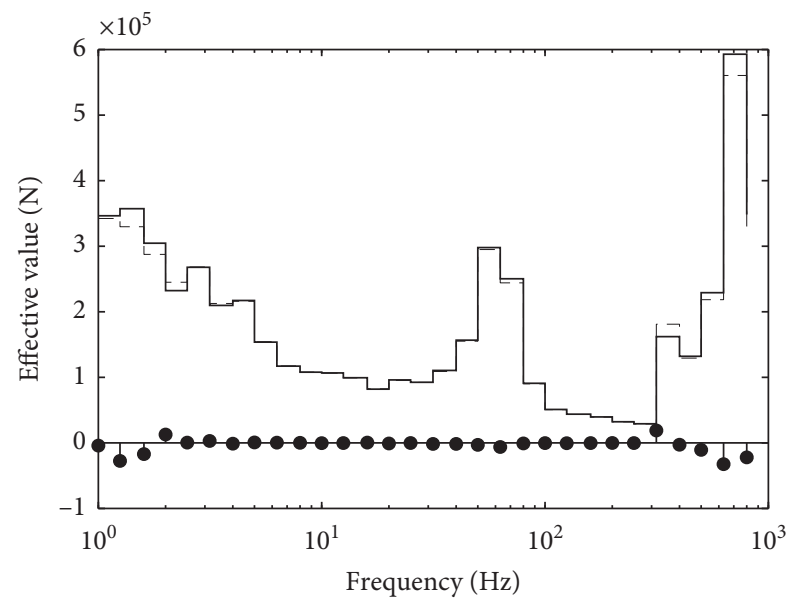

Figure 13: 1/3 Octave band of the wheel-rail contact force (under practical differential settlement; --- under theoretical differential settlement; - differences between two cases). with the tunnel settlement length $\lambda_{0}$ assumed as $10 \mathrm{~m}, 50 \mathrm{~m}$, $100 \mathrm{~m}, 150 \mathrm{~m}$ and $200 \mathrm{~m}$, respectively. In each case, the maximum carriage acceleration and the minimum wheelrail contact force are discussed due to different settlement depths, as shown in Figures 14 and 15. The speed of the metro train is still assumed as $72 \mathrm{~km} / \mathrm{h}$.

As shown in Figure 14(a), when the settlement length is relatively small, the maximum carriage acceleration increases linearly with the increase of the tunnel settlement depth. However, for the settlement length larger than $150 \mathrm{~m}$, no obvious changes can be observed. The minimum wheelrail contact force decreases significantly with increase of settlement depth, as shown in Figure 14(b). For the settlement depth-to-length ratio $\left(h_{0} / \lambda_{0}\right)$ larger than $1 / 625$, the contact force becomes zero and the train derailment may occur in this case. Therefore, the tunnel settlement with a large depth-to-length ratio has adverse influence on the vibration of the metro train-track system, which may threaten the safety of subway operation.

The effects of train speed on the carriage acceleration and wheel-rail contact force are also studied, as shown in Figure 15 . Here, the wavelength of the tunnel settlement is taken as $\lambda_{0}=100 \mathrm{~m}$. It can be observed from Figure 15(a) that the maximum carriage acceleration increases obviously with the increase of train speed. It is also found that the maximum carriage acceleration is very sensitive to the settlement depth for the train traveling at a higher speed. However, the effect of the settlement depth on the maximum carriage acceleration can be negligible when the train speed is lower than $20 \mathrm{~m} / \mathrm{s}$. The minimum wheel-rail contact force due to different train speeds is shown in Figure 15(b). With the increase of train speed and settlement depth, the wheel-rail contact force decreases significantly, or even becomes zero, which is dangerous for the train operation.

According to the Code for Design of Metro in China (GB50157-2013) [22], the train safety and passengers' comfort indicators should satisfy the following requirements: 


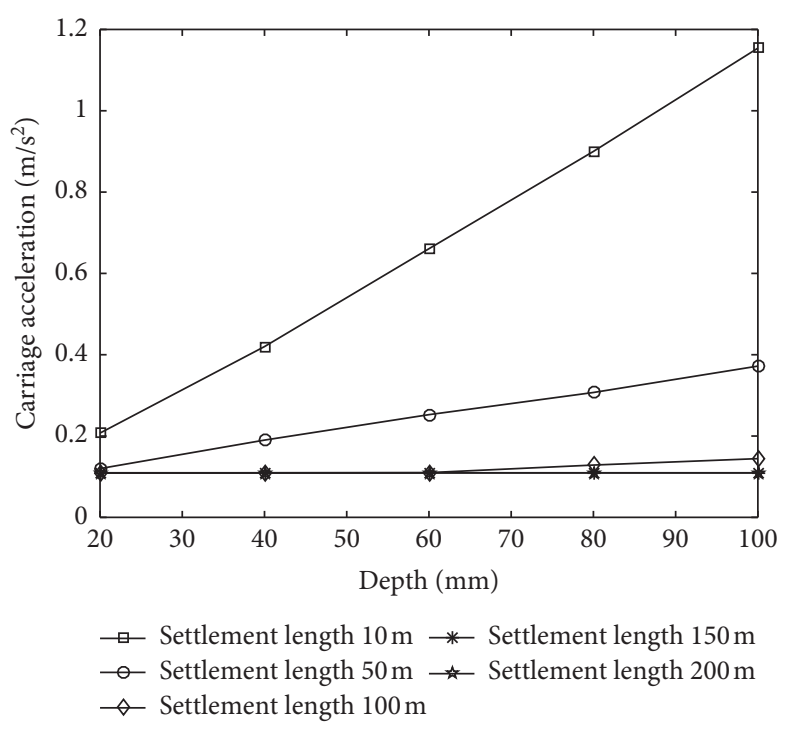

(a)

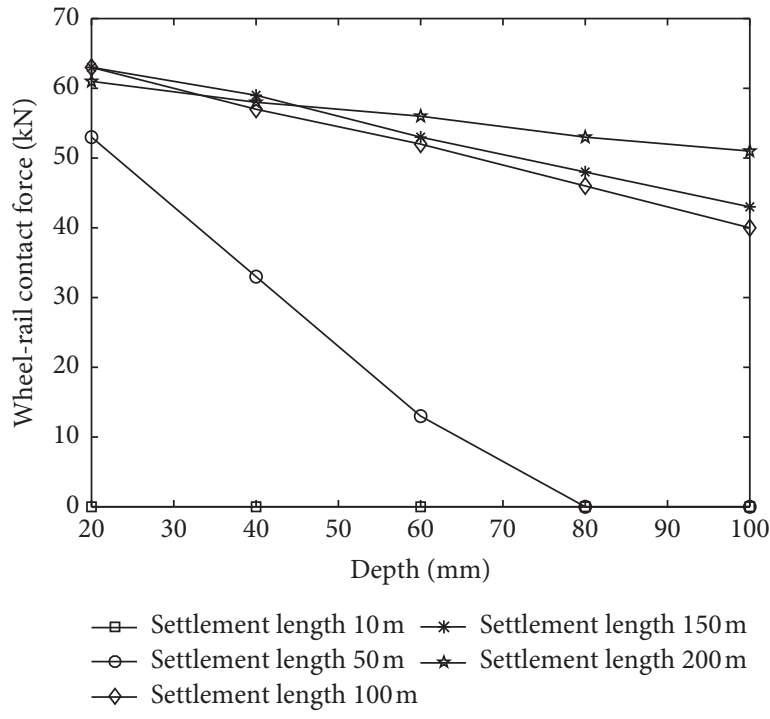

(b)

Figure 14: Metro train-track vibration under different tunnel differential settlements. (a) Maximum acceleration of the carriage. (b) Minimum wheel-rail contact force.

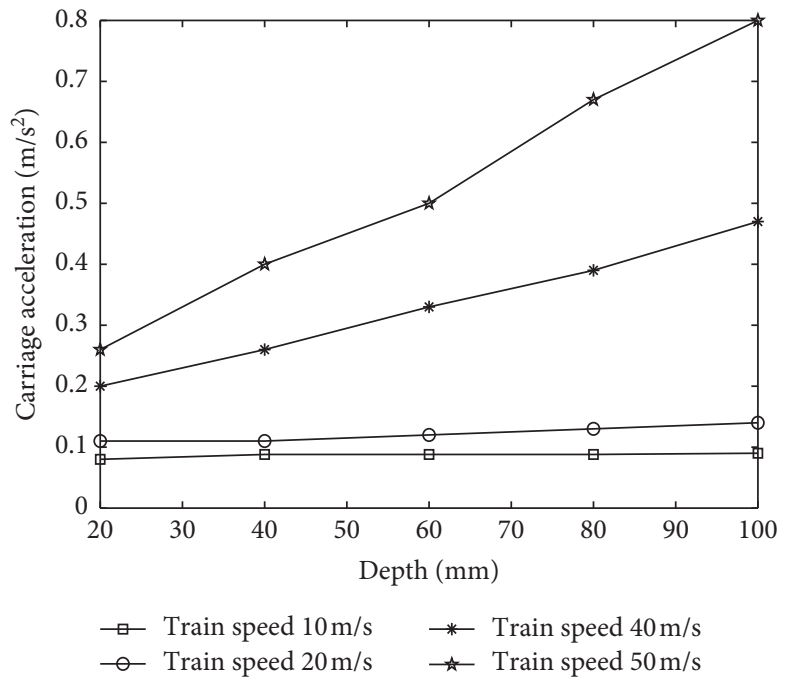

(a)

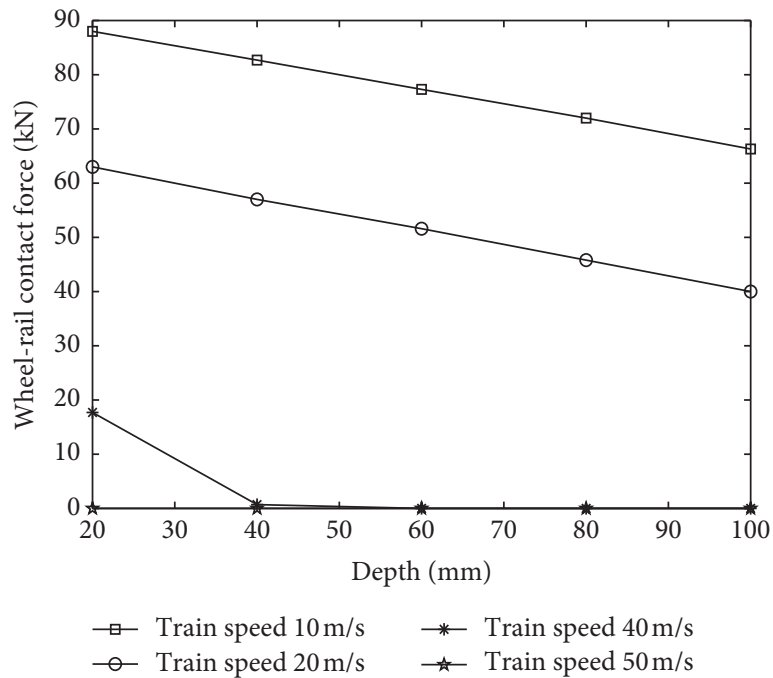

(b)

Figure 15: Effects of train speed on metro train-track vibration with tunnel differential settlement (settlement length $\lambda_{0}=100 \mathrm{~m}$ ). (a) Maximum acceleration of the carriage. (b) Minimum wheel-rail contact force.

$$
\begin{aligned}
a_{z} & \leq 0.13 g, \\
\frac{\Delta P}{\bar{P}} & \leq 0.6,
\end{aligned}
$$

where $a_{z}$ is the carriage acceleration; $g$ is the gravity acceleration taken as $9.8 \mathrm{~m} / \mathrm{s}^{2}$; and $\Delta P$ is the reduction of wheel load and $\bar{P}$ is the average wheel load (usually taken as the static wheel weight).

The vibration responses of the train-monolithic bed track system under different settlement distributions and different train speeds are calculated here. Based on equation (14), we can finally conclude the speed limit for the metro train traveling on the monolithic bed track with different settlement distributions, as listed in Table 4.

It can be seen from Table 4 that the speed limit of the train decreases correspondingly with the increase depth of the tunnel settlement. It should be noted that the train speed limit shown in Table 4 is only suitable for the metro trainmonolithic bed track system discussed in this paper. Actually, the speed limit of the metro train is decided by many factors, including the material and geometric parameters of the train-track system, the soil parameters, and the practical distribution curve of the tunnel differential settlement. However, the methods presented in this paper can be extended easily to other cases and the train speed limit 
TABle 4: Speed limit of the metro train due to different tunnel differential settlements.

\begin{tabular}{lcccc}
\hline \multirow{2}{*}{ Depth $(\mathrm{mm})$} & \multicolumn{4}{c}{ Settlement length $(\mathrm{m})$} \\
& 50 & 100 & 150 & 200 \\
\hline 20 & $20 \mathrm{~m} / \mathrm{s}$ & $24 \mathrm{~m} / \mathrm{s}$ & $24 \mathrm{~m} / \mathrm{s}$ & $23 \mathrm{~m} / \mathrm{s}$ \\
40 & $16 \mathrm{~m} / \mathrm{s}$ & $22 \mathrm{~m} / \mathrm{s}$ & $22 \mathrm{~m} / \mathrm{s}$ & $22 \mathrm{~m} / \mathrm{s}$ \\
60 & $13 \mathrm{~m} / \mathrm{s}$ & $20 \mathrm{~m} / \mathrm{s}$ & $20 \mathrm{~m} / \mathrm{s}$ & $21 \mathrm{~m} / \mathrm{s}$ \\
80 & $11 \mathrm{~m} / \mathrm{s}$ & $17 \mathrm{~m} / \mathrm{s}$ & $19 \mathrm{~m} / \mathrm{s}$ & $20 \mathrm{~m} / \mathrm{s}$ \\
100 & $9 \mathrm{~m} / \mathrm{s}$ & $15 \mathrm{~m} / \mathrm{s}$ & $17 \mathrm{~m} / \mathrm{s}$ & $19 \mathrm{~m} / \mathrm{s}$ \\
\hline
\end{tabular}

calculated due to different cases can be a theoretical reference for the safety operation of the metro system.

\section{Conclusions}

In summary, the vibration responses of the metro trainmonolithic bed track system under tunnel differential settlement are analyzed based on a two-dimensional dynamic model. The effects of a practical tunnel differential settlement on the dynamic responses of the train-track system are studied. According to the curvature of the practical settlement curve, a cosine function is introduced for modelling the practical tunnel settlement. Based on this cosine model, the vibration responses of the train-track system under different tunnel settlement distributions are further investigated, and the speed limit of a metro train is obtained based on the requirements for the train safety and passengers' comfort.

(1) The tunnel differential settlement has a great influence on the carriage acceleration, the wheel-rail contact force, and the rail acceleration but has little effect on the rail displacement.

(2) The tunnel differential settlement can amplify the dynamic responses of accelerations and forces in the high-frequency range, which may enhance the environment noise.

(3) The dynamic responses of the metro train-track system will increase significantly with the increase of the train speed and settlement depth but will decrease with the increasing settlement length.

(4) According to the train safety and passengers' comfort, the speed limit of a metro train can be obtained under different settlement distributions, which can provide a reference for subway operation.

It should be noted that the dynamic response of the metro train-track system is highly dependent on the material and geometric parameters of the train-track system. Therefore, the quantitative results obtained in this paper are mainly suitable within the range of parameters considered in this paper. However, the method used in this paper can be easily extended for vibration analysis of other train-track structures.

\section{Data Availability}

All the underlying data related to this article are available from the corresponding author upon request.

\section{Conflicts of Interest}

The authors declare no conflicts of interest with respect to the research, authorship, and/or publication of this article.

\section{Acknowledgments}

This work was supported by the Zhejiang Provincial Natural Science Foundation of China (Grant no. LY17E080005), the National Natural Science Foundation of China (Grant no. 51778576), and the Hangzhou Science and Technology Plan Project (Grant nos. 20191203B40 and 20172016A06).

\section{References}

[1] Y. B. Yang and L. C. HSU, "A review of researches on groundborne vibrations due to moving trains via underground tunnels," Advances in Structural Engineering, vol. 9, no. 3, pp. 377-392, 2006.

[2] H. Xia, Y.-M. Cao, and N. Zhang, "Numerical analysis of vibration effects of metro trains on surrounding environment," International Journal of Structural Stability and Dynamics, vol. 7, no. 1, pp. 151-166, 2007.

[3] D.-Y. Ding, S. Gupta, W.-N. Liu, G. Lombaert, and G. Degrande, "Prediction of vibrations induced by trains on line 8 of Beijing metro," Journal of Zhejiang University Science A, vol. 11, no. 4, pp. 280-293, 2010.

[4] H.-N. Wu, Y.-S. Xu, S.-L. Shen, and J.-C. Chai, "Long-term settlement behavior of ground around shield tunnel due to leakage of water in soft deposit of Shanghai," Frontiers of Architecture and Civil Engineering in China, vol. 5, no. 2, pp. 194-198, 2011.

[5] S.-L. Shen, H.-N. Wu, Y.-J. Cui, and Z.-Y. Yin, "Long-term settlement behaviour of metro tunnels in the soft deposits of Shanghai," Tunnelling and Underground Space Technology, vol. 40, pp. 309-323, 2014.

[6] C. W. W. Ng, G.-B. Liu, and Q. Li, "Investigation of the longterm tunnel settlement mechanisms of the first metro line in Shanghai," Canadian Geotechnical Journal, vol. 50, no. 6, pp. 674-684, 2013.

[7] M. L. Cooper, D. N. Chapman, C. D. F. Rogers, and A. H. C. Chan, "Movements in the Piccadilly Line tunnels due to the Heathrow Express construction," Géotechnique, vol. 52, no. 4, pp. 243-257, 2002.

[8] C. R. I. Clayton, J. P. Van Der Berg, and A. H. Thomas, "Monitoring and displacements at Heathrow Express terminal 4 station tunnels," Géotechnique, vol. 56, no. 5, pp. 323-334, 2006.

[9] Q. Huang, H.-W. Huang, B. Ye, D.-M. Zhang, and F. Zhang, "Evaluation of train-induced settlement for metro tunnel in saturated clay based on an elastoplastic constitutive model," Underground Space, vol. 3, no. 2, pp. 109-124, 2018.

[10] R. D. Fröhling, W. Ebersönhn, and H. Scheffel, "Measurement and prediction of vehicle/track interaction performance," International Journal of Heavy Vehicle Systems, vol. 6, no. 1, 1999.

[11] Y. Momoya, E. Sekine, and F. Tatsuoka, "Deformation characteristics of railway roadbed and subgrade under moving-wheel load," Soils and Foundations, vol. 45, no. 4, pp. 99-118, 2005.

[12] T. Abadi, L. Le Pen, A. Zervos, and W. Powrie, "A review and evaluation of ballast settlement models using results from the Southampton railway testing facility (SRTF)," Procedia Engineering, vol. 143, pp. 999-1006, 2016. 
[13] Q. Huang, H.-W. Huang, B. Ye, D.-M. Zhang, L.-L. Gu, and F. Zhang, "Dynamic response and long-term settlement of a metro tunnel in saturated clay due to moving train load," Soils and Foundations, vol. 57, no. 6, pp. 1059-1075, 2017.

[14] Z. Jiang, G.-Y. Gao, H.-F. Dai, and H. Liu, "Influence of differential subgrade settlement on metro tunnel structure under train load," Chinese Journal of Underground Space and Engineering, vol. 10, no. 6, pp. 1433-1439, 2014.

[15] K. L. Knothe and S. L. Grassie, "Modelling of railway track and vehicle/track interaction at high frequencies," Vehicle System Dynamics, vol. 22, no. 3-4, pp. 209-262, 1993.

[16] K. Popp, H. Kruse, and I. Kaiser, "Vehicle-track dynamics in the mid-frequency range," Vehicle System Dynamics, vol. 31, no. 5-6, pp. 423-464, 1999.

[17] A. A. Shabana and J. R. Sany, "A survey of rail vehicle track simulations and flexible multibody dynamics," Nonlinear Dynamics, vol. 26, no. 2, pp. 179-212, 2001.

[18] V. K. Garg and R. V. Dukkipati, Dynamics of Railway Vehicle Systems, Academic Press, Ontario, Canada, 1984.

[19] J.-C. Wei, P. He, and Y.-J. Li, "Analysis on the vibration attenuation of metro steel spring floating slab track," Journal of the China Railway Science, vol. 33, pp. 17-24, 2012.

[20] D. J. Thompson, "Wheel-rail noise generation, part I: introduction and interaction model," Journal of Sound and Vibration, vol. 161, no. 3, pp. 387-400, 1993.

[21] S. L. Grassie, R. W. Gregory, D. Harrison, and K. L. Johnson, "The dynamic response of railway track to high frequency vertical excitation," Journal of Mechanical Engineering Science, vol. 24, no. 2, pp. 77-90, 1982.

[22] China Construction Industry Press, Code for Design of Metro GB50157-2013, China Construction Industry Press, Beijing, China, 2013. 